\title{
O JOGAR INFANTIL E SUAS DIMENSÕES METAFÍSICAS: UMA RELEITURA DE TRÊS PASSAGENS DE “INFÂNCIA EM BERLIM POR VOLTA DE 1900”
}

Dirceu Ribeiro Nogueira da Gama

\section{RESUMO}

O objetivo do presente estudo foi investigar três passagens da obra "Infância em Berlim por volta de 1900", intituladas "O carrossel", "Caçando borboletas" e "Esconderijos". Os pressupostos a guiarem essa investigação são os de que tais passagens constituem registros de memória de Walter Benjamin acerca de jogos que ele costumava realizar quando criança, e que, segundo o autor, jogos são meios de acesso metafísico a mundos alternativos. As supracitadas passagens foram respectivamente analisadas e comentadas a partir de diálogos com Roger Caillois, Geroges Bataille e Gaston Bachelard. Conclui-se que as atividades lúdicas, na perspectiva de Benjamin, promovem transformações éticas, estéticas e epistemológicas no sujeito; oportunizam a mimetização da realidade e estimulam a criação de alegorias. Dessa forma, condizem elas com estados metamórficos do ser. Tal ideia também faz-se presente em textos de Eugen Fink, Heráclito de Éfeso e Nietzsche. Recomenda-se que futuras investigações verifiquem se outros aforismas escritos por Benjamin em "Infância em Berlim por volta de 1900" ou mesmo "Rua de Mão Única" se debruçam sobre a mesma temática. No mais, o presente estudo fornece argumentos que endossam a relevância educacional de pedagogias lúdicas e centradas no estímulo à mimetização.

Palavras-chaves: Jogo. Infância. Metafísica. Faculdade Mimética. Alegoria.

\section{CHILDREN'S PLAY AND ITS METAPHYSICAL DIMENSIONS: A REVIEW OF THREE PASSES FROM "CHILDHOOD IN BERLIN CIRCA 1900"}

\begin{abstract}
The purpose of this study was to investigate three passages of the work "Childhood in Berlin around 1990", named "The Carousel", "Butterfly Hunt" and "Hiding Places". The assumptions guiding this research are that these passages constitute Walter Benjamin's memory records of games he used to play as a child, and that, according to the author, games are means of metaphysical access to alternative worlds. The above passages have been analysed and commented on respectively through discussions with Roger Caillois, Geroges Bataille and Gaston Bachelard. It is concluded that the playful activities, from Benjamin's perspective, promote subjective transformations of an ethical, aesthetic and epistemological nature; lead to the creative mimicking of the reality and stimulate the creation of allegories. In this way, they correspond to metamorphic states of being. This idea is also present in texts written by Eugen Fink, Heraclitus of Ephesus and Nietzsche. It is recommended that future Doutor em Filosofia pela Universidade Gama Filho; e-mail: dirceurng@gmail.com. Brasileiro, residente no Rio de Janeiro - RJ.
\end{abstract}


research should check whether other aphorisms written by Benjamin in "Childhood in Berlin around 1900" or even "One Way Street" address the same topic. In addition, this study provides arguments endorsing the educational relevance of playful pedagogies and focusing on the stimulation of mimetization.

Keywords: Game. Childhood. Metaphysics. Mimetic faculty. Allegory.

\section{Introdução}

Nas "Teses sobre a Filosofia da História”, redigidas em 1940, Walter Benjamin declara, na de número seis, que articular historicamente o passado não significa conhecê-lo tal como ele foi efetivamente, pois a comunicação do que já aconteceu sempre envolve a subjetividade do narrador. (BENJAMIN, 1992). Para resolver essa aporia e, ao mesmo tempo, endossar a credibilidade dos discursos históricos, Benjamin propõe a tese de que o passado disponibiliza apenas rastros do que ocorrera.

De Platão à Derrida, o conceito de rastro versa sobre a presença do ausente e as ausências da presença (GAGNEBIN, 2006). Na confluência desse estado de tensão, situa-se a memória, porquanto quem decide revisitar o passado, não obstante o motivo, o faz a partir de um agora também evanescente. Portanto, falar das situações de outrora pressupõe tão apenas colher vestígios não apagados das profundezas mnemônicas. Se por um lado essa relação é inegavelmente frágil, por outro, apenas ela viabiliza o combate ao esquecimento (GAGNEBIN, 2006).

$\mathrm{Na}$ ótica de Scholem (1994), Benjamin equacionou concretamente esse paradoxo nos seminais escritos "Rua de Mão Única" e "Infância em Berlim por volta de 1900". Em tais textos, inúmeras recordações de infância são recuperadas e relatadas sem critérios de utilidade ou lógica. Sobre "Rua de Mão Única", Scholem (1994, 186-187) declara que o impulso de descoberta do inusitado em micromundos permeia a totalidade do texto: "Criar ou descobrir perfeição (...) na menor escala era um de seus impulsos mais fortes. (...) Esta inclinação empresta nota especial ao seu volume Rua de Mão Única. Pois o que importa (...) é (...) apresentar em breves ditos (...) algo completo em si mesmo." O aforisma tornou-se a estratégia de redação escolhida por Benjamin para tal propósito. Em se tratando de "Infância em Berlim por 
volta de 1900", diz Scholem $(1994,185)$ que a influência de Proust foi um de seus pilares.

\begin{abstract}
Para Benjamin, a obra de Proust marca o ponto onde o mundo dos adultos e o das crianças se fundem de modo mais perfeito e de acordo com um dos pontos cardeais de seu interesse filosófico. Finalmente, esta fascinação encontrou uma saída nas recordações de sua própria infância que ele registrou na primeira metade dos anos 30 sob o título (...) Infância em Berlim por volta de 1900. (...) Aqui, a poesia e a realidade tornam-se uma só.
\end{abstract}

Scholem $(1989,79)$ em igual assevera que Walter Benjamin tinha um lado profundamente metafísico. "Benjamin (...) era um grande metafísico (...). Escrevi na época: 'Por mais que a vida [de Benjamin] seja (...) a única que foi vivida metafisicamente diante de mim, (...) ela contém (...) os elementos (...) de (...) um certo limite difícil de definir." Adorno $(1992,10)$ reitera o mesmo ponto de vista, acrescentando que o método e o estilo de escrita de Benjamin nunca deixaram de espelhar tal viés, ora de maneira sutil, ora explícita: "Diante da sua insistência, dissolvia-se o indissolúvel, e Benjamin apoderava-se da essência das coisas precisamente nos pontos em que o muro da simples factualidade esconde (...) tudo o que é essencial."

Feita essa observação, em "Rua de Mão Única" o leitor depara-se com registros que variam de encontros de rua, jogos, brincadeiras e acontecimentos escolares à descrições de paisagens urbanas e de outras situações corriqueiras do dia a dia. No entanto, a obra não deve ser confundida literatura autobiográfica ou tampouco idealizações de alguém revisitando a época de criança (GAGNEBIN, 2005). O que Benjamin realiza nesse texto é a proposição da infância como possibilidade de absorção do real sem a plena mediação do logos. A fantasia e o devaneio são os fatores a abalizarem as suas compreensões. Já em "Infância em Berlim por volta de 1900", o filósofo expõe detalhadamente a sua incapacidade de entender certas palavras ou as funções de determinados objetos nos tempos de criança (GAGNEBIN, 2005). Mas o que seria uma suposta fragilidade acaba compensada por uma percepção peculiar dos objetos desprezados pelos adultos. Esse olhar privilegiado enxerga o cotidiano de janelas, estátuas públicas, luminárias, portas etc. pelas lentes de uma criatividade que reinventa sem cessar os sentidos desses artefatos. 
Particularmente, no aforisma "Canteiro de Obras", de "Rua de Mão Única", Benjamin $(1995,18-19)$ relata que jogos e brincadeiras constituem atividades chaves para quem quiser entender a maneira autêntica e livre das crianças intercederem no mundo. Malgrado os adultos pouco atentarem para isso, durante tais atividades o ser do infante se exibe efetivamente como é: pura potência inventiva.

Elucubrar pedantemente sobre a fabricação de objetos - material educativo, brinquedos ou livros - que fossem apropriados para crianças é tolice. Desde o lluminismo essa é uma das mais bolorentas especulações dos pedagogos. Seu enrabichamento pela psicologia impede-os de reconhecer que a Terra está repleta dos mais incomparáveis objetos de atenção e exercício infantis. E dos mais apropriados. Ou seja, as crianças são inclinadas de modo especial a procurar todo e qualquer lugar de trabalho onde (...) transcorre a atividade sobre as coisas. Sentem-se irresistivelmente atraídas pelo resíduo que surge na construção, (...) na costura ou marcenaria. Em produtos residuais reconhecem o rosto que o mundo das coisas volta para elas (...). Neles, elas menos imitam as obras dos adultos do que põem materiais de espécie muito diferente, através daquilo que com eles aprontam no brinquedo, em uma nova, brusca relação entre si. Com isso as crianças formam para si seu mundo de coisas, um pequeno no grande, elas mesmas.

O artista plástico Paul Klee, por quem Benjamin nutriu intensa admiração, também comungava dessa ideia. No contato lúdico com as coisas, dizia Klee (apud Klee, 1962, 183-184), as crianças descortinam caminhos que conduzem a realidades alternativas. Chamando-as de "mundos intermediários", o artista apregoava a impossibilidade do indivíduo adulto penetrá-los. Na sua leitura, isso não acontecia com o infante, o selvagem primitivo e o louco.

In our time worlds have opened up which not everybody can see into, although
they are too part of nature. Perhaps it's really true that only children, madmen
and savages see into them. I mean, for example, the realm of the unborn and
the dead, the realm of what can be, might be, but need not necessarily be. An
in-between world. At least for me, it's an in-between world. I call it that because
I feel that it exists between the worlds our senses can perceive, and I absorb
it inwardly to the extent that I can project it outwardly in symbolic
correspondences. Children, madmen and savages can still, or again, look into
it. And what they see and picture is for me the most precious kind of
confirmation.

Em síntese, vê-se que, não obstante cada qual observar a partir de um ponto de vista próprio, tanto Benjamin como Paul Klee põem os jogos e brincadeiras ${ }^{1}$ na

\footnotetext{
${ }^{1}$ No idioma alemão, o vocábulo spiele é usado simultaneamente para denominar o que em língua portuguesa recebe a tradução de "jogo" e "brincadeira". Além disso, o verbo spielen, relacionado a esse Doutor em Filosofia pela Universidade Gama Filho; e-mail: dirceurng@gmail.com. Brasileiro, residente no Rio de Janeiro - RJ.
} 
condição de veículos de acesso metafísico a mundos diferenciados. Nesse sentido, é possível estimar que nas memórias de infância de Benjamin comunicadas em "Rua de Mão Única" e "Infância em Berlim por volta de 1900" é possível encontrar rastros dessa experiência. Feito esse diagnóstico, o objetivo do presente estudo consiste então em explorar tal questão, demarcando-a na análise de três passagens de "Infância em Berlim por volta de 1900", intituladas "O carrossel”, "Caçando borboletas" e "Esconderijos".

\section{A brincadeira de carrossel}

Em "O Carrossel”, Benjamin $(1995,106)$ narra um acontecimento que deve ter se repetido mais de uma vez em seus anos de criança: girar neste brinquedo. Assim que começava o rodopio, a sensação de voar aparecia. "O tablado com os solícitos animais girava muito próximo ao chão. Tinha a altura na qual melhor se sonha sair voando." O início do giro da prancha, seguido de uma música, provocava medo. Mas com a velocidade de giro aumentando, os receios sumiam, havendo a entrega plena à nova situação. "A música irrompia, e o menino girava às sacudidelas, afastando-se da mãe. No início, tinha medo de abandoná-la. Mas depois percebia como era fiel a si próprio. Está sentado no trono, como leal soberano, governando o mundo que lhe pertencia." (BENJAMIN, 1995, 106).

Pode-se dizer que uma transição de estados pessoais tinha início com a retirada do brinquedo da inércia por meio do giro. Com efeito, as clássicas investigações de Caillois (1990) sobre os jogos humanos são esclarecedoras quanto a essa situação. Jogos de rodar receberam do autor o nome de ilinx, vocábulo grego que significa turbilhão provocador de vertigens. Caillois $(1990,43)$ coloca que o principal efeito das brincadeiras giratórias é a brusca suspensão da consciência corrente de espaço e de tempo. "Cada criança sabe (...) que, ao rodar rapidamente, atinge um estado centrífugo, (...) de fuga e de evasão, em que, a custo, o corpo reencontra o seu equilíbrio e a percepção a sua nitidez. Não há qualquer dúvida de que a criança o faz por brincadeira e sente prazer com isso." Assevera Caillois (1990) que o rodopio propicia uma dupla evasão, material e estética, a qual se segue outra,

substantivo, possui, dentre outros significados, o de "brincar", "jogar", assim como "representar" papéis. Para os fins do nosso estudo, considerar-se-á brincar e jogar como palavras análogas. 
de cunho ético-moral. "Existe, em paralelo, uma vertigem de ordem moral, que se apodera subitamente do indivíduo. Essa vertigem associa-se habitualmente ao gosto (...) pela desordem e pela destruição" (CAILLOIS, 1990, 43).

Os giros acionavam a imaginação de Benjamin. $O$ antes e o agora deixavam de ser vinculados de modo linear para se condensarem na brevidade do instante. "Nas tangentes, árvores e indígenas formavam uma guarda de honra. De súbito, reaparecia a mãe nalgum Oriente. Em seguida, emergia da floresta virgem uma copa de árvore, tal como o garoto a vira há milênios, tal qual a via justamente agora." (BENJAMIN, 1995, 106). Conclui-se que os efeitos do movimento circular eram duplos, pois modificavam os posicionamentos relativos dos objetos físicos e reabriam a memória.

Personagens de conhecidas estórias antigas reavivavam-se na esfera corporal, tal qual entidades encarnadas. "Seu animal se mancomunava com ele: como um Árion mudo, ele se ia montado em seu peixe mudo, um Zeus taurino de madeira o raptava como á imaculada Europa." (BENJAMIN, 1995, 106). Novamente, Caillois fornece subsídios teóricos de valia para a compreensão desse acontecimento, ao sublinhar que o ilinx permite experiências de mimicry, ou seja, oferece ao indivíduo a oportunidade de assumir-se outrem:

\begin{abstract}
O jogo pode consistir (...) na encarnação de um personagem ilusório e na adoção do respectivo comportamento. Encontramo-nos, então, perante (...) manifestações que têm como característica comum a de se basearem no fato de o sujeito jogar a crer e a fazer crer a si próprio ou (...) aos outros que é outra pessoa (...). Decidi designar estas manifestações pelo termo mimicry (...). E, finalmente, é claro que a representação teatral e (...) dramática entram de direito neste grupo. O prazer é o de ser outro ou de se fazer passar por outro. $(1990,39-41)$
\end{abstract}

Inicialmente, os giros do carrossel fizeram Benjamin ter a sensação de ser Aríon, o mitológico músico de Lesbos. Diz o mito que um dia, Periandro, tirano de Corinto e seu protetor, permitiu-Ihe percorrer a Magna Grécia e a Sicília para cantar. Depois de um longo período viajando, Árion decide retornar à terra natal. Para isso, embarca em um navio. Vendo que Árion carregava grande quantidade de dinheiro consigo, os marinheiros decidem roubá-lo e atirá-lo ao mar. Comunicado do que lhe ocorreria, Árion solicita permissão para uma última canção, no que foi aceito. Ao ouvirem a bela voz vinda do convés, golfinhos cercaram a embarcação. Tão logo a 
tripulação atirou-o às águas, um dos animais impediu o seu afogamento e, deixandose montar, conduzindo o poeta até Corinto (GRIMAL, 2000).

Em relação a Europa, a personagem a que Benjamin se reporta é a filha de Agenor e Telefassa. Numa manhã em que caminhava em praias de Sídon, reino de seu pai, a bela jovem chamou a atenção de Zeus. Decidido a possui-la, o monarca do Olimpo transformou-se num touro branco de chifres em formato de lua crescente e desceu à areia. Aproximando-se sutilmente, conquistou a confiança de Europa, que resolveu montá-lo. Tão logo a princesa acomodou-se, o animal disparou até a água e nadou até a ilha de Creta. Lá, Zeus recobrou a forma de homem e consumou o seu amor pela jovem (GRIMAL, 2000).

Mesmo reconhecendo que as figuras míticas do Zeus-Touro e do golfinho salvador admitem muitas interpretações, Chevalier \& Gheerbrant (2002) outrossim identificam complementaridades hermenêuticas entre elas. O touro branco lunar remete à vida como potência generativa no fluxo do tempo, entendido como sucessões de ciclos intermináveis. Seu sentido é o da esperança renovadora que não se abate diante das adversidades opressoras que se avolumam. Sobre o golfinho responsável por resgatar Árion, os autores frisam a sua condição de redentor dos agredidos pela violência mundana. Portanto, a conjunção do par golfinho-touro denota o diálogo da esperança com a salvação. Ou, em outras palavras, a esperança de ser salvo. Intrínsecos à existência humana, Benjamin coloca que a mobilização desses valores nas circunstâncias lúdicas do ilinx e mimicry é da ordem de um eterno retorno. "Fazia tempo que o eterno retorno das coisas se tornara sabedoria infantil (...)." (BENJAMIN, 1995, 106).

Ora, a suposição de que a salvação e a esperança significados no binômio golfinho-touro constituem valores eternamente restituídos às tessituras do cotidiano também percorre diversos trechos da Torá, o livro sagrado dos judeus (CROMBERG, 2002). Para diversos intérpretes da religião judaica, é inegável que esperança e salvação irmanam-se à noção de justiça (IBID). Na perspectiva de Scholem (1989), essa é a ideia culminante dos Dez Mandamentos anunciados por Javé ao Profeta Moisés. Recorda-se o autor de uma conversa que teve com Benjamin e sua esposa Dora entre 1918 e 1919, onde o primeiro mostrou-se bastante impressionado diante de tal fato. "Um dia, nós três tivemos uma conversa longa sobre os Dez Mandamentos 
(...) e sobre os significados dos preceitos da Torá. Li para eles algumas notas sobre o conceito de justiça (...) [que] provocaram em Benjamin uma reação muito forte." (SCHOLEM, 1989, 80).

A Torá preconiza que o culto da esperança e da salvação, enquanto fundamentos morais da justiça, há que acontecer em ritos coletivos, por meio dos quais a comunidade dos hebreus deve suspender as suas atividades para refundar a fé na vinda do Messias, que pode ocorrer a qualquer momento. A crença em tal possibilidade preenche o agora de pleno sentido e o faz ficar gravado para sempre na existência de quem vivencia essa experiência. Benjamin nomeia esse evento de Jetztzeit. "É na fulgurância do agora (Jetztzeit) que o passado retorna, de improviso, porque é (...) uma das ex-stases da temporalidade, que não tem como ponto de partida a (...) consciência e não pode ser constituído por ela. É (...) o que ela esquece para se constituir a si mesma." (MATOS, 1990, 300).

As verdades do Jetztzeit não são da ordem do pensamento racional, pois emergem de rememorações surgidas ao sabor do acaso. Nada do que aconteceu nos tempos idos está descartado. Nas "Teses sobre a Filosofia da História", Benjamin $(1992,58)$, na de número três, extrapola essa colocação para toda a humanidade. Os homens só poderão se apropriar de todos os matizes do itinerário civilizatório quando estiverem cientes dos impedimentos que obstruíram e ainda obstruem a vontade coletiva de felicidade.

\footnotetext{
O cronista que narra os acontecimentos, sem distinguir entre os grandes e os insignificantes, tem em conta, fazendo isso, a seguinte verdade: nada daquilo que alguma vez aconteceu deve ser considerado como perdido para a história. Certamente só à humanidade redimida pertence plenamente o seu passado. Isto quer dizer que apenas para ela, em cada um dos seus momentos, o passado se tornou citável. Cada um dos instantes que ela viveu torna-se uma citation à l'ordre du jour - e esse dia é precisamente o último (BENJAMIN, 1992, 158).
}

Em resumo, o relato de Benjamin em "O Carrossel" começa com menções à capacidade do brinquedo homônimo conseguir desordenar espaços e tempos. Por intermédio das circunvoluções, o filósofo, ainda infante, imaginava-se realizando os feitos de seres míticos. Por seu turno, os discursos descrevendo essa sensação continham alusões aos valores da salvação e redenção, cuja emergência no mundo, 
de acordo com a mística judaica, chama-se Jetztzeit e não admite previsões ou antecipações.

\section{A caça às borboletas}

Em "Caçando borboletas", Benjamin (1995, 80-82) discorre sobre o hábito de caçar borboletas, o qual ocorria todos os anos em que ele e seus pais gozavam férias nas redondezas de Berlim. Esse costume remontava a épocas ainda anteriores, de quando a família se reunia em uma casa de veraneio nas imediações da montanha Brauhausberg, em Potsdam.

Benjamin acreditava, quando criança, que um caçador de borboletas deveria saber confundir-se com o ar e a luz, porque isso lhe facilitaria a captura dos insetos. "Esvoaçavam em direção a uma flor, pairavam sobre ela (...). Com a rede levantada, esperava tão-só (...) dissolver-me em luz e em ar a fim de me aproximar da presa sem ser notado e poder dominá-la." (BENJAMIN, 1995, 81).

Caillois (1990) situa a caça no rol dos jogos de agon clássicos. Neles, os participantes combatem um ao outro com o intento de discernirem quem é de fato o melhor. Por sua vez, assim como o ilinx do carrossel, o agon também pode associarse à mimicry: "A luta tem as suas peripécias, que correspondem aos diferentes atos ou episódios de um drama. $\mathrm{E}$ (...) a mimicry não só não prejudica o princípio do agon como o reforça, dada a necessidade de cada jogador (...) representar-se (...) o melhor possível (...)." (CAILLOIS, 1990, 95-96). Portanto, a aquisição de invisibilidade insurgia como imperativo para uma caça profícua por corresponder a um singular tipo de mimicry.

Todas as vezes que conseguia se aproximar do inseto, Benjamin $(1995,81)$ tinha a sensação de seus corpos se fundirem. "Entre nós começava a se impor o antigo estatuto da caça: quanto mais me achegava com todas as fibras ao inseto (...) mais assumia a essência da borboleta (...)." Isso significa que a interação entre o perseguidor e a presa na atmosfera do jogo de agon da caça pressupunha confronto e complementaridade. Benjamin sabia como reverter tal quadro. "[Era] como se a sua captura fosse o único preço pelo qual minha condição de homem pudesse ser reavida." (BENJAMIN, 1995, 81). De certa forma, tal juízo remonta àquilo que Bataille (2004, 141) chamou de lógica sacrifical:

Doutor em Filosofia pela Universidade Gama Filho; e-mail: dirceurng@gmail.com. Brasileiro, residente no Rio de Janeiro - RJ. 
O sacrifício (...) é a ação deliberada cujo fim é a mudança do ser que dele é a vítima. Esse ser foi morto. Antes de ter sido morto, ele estava encerrado na particularidade individual (...) [porque] sua existência era então descontínua. Mas esse ser, na morte, é reconduzido à continuidade do ser, à ausência de particularidade. Essa ação (...) priva a vítima de seu caráter limitado e confere-lhe o ilimitado, o infinito que pertence à esfera sagrada.

Todo sacrifício pressupõe a efetivação de uma troca simbólica, no sentido de que a oferta de dádivas para entidades espirituais tem, como contrapartida, alguma retribuição compensatória. O desvelamento de verdades radicadas nos recônditos do Ser consiste na mais elevada delas.

\begin{abstract}
A morte (...) para nós, que somos seres descontínuos, (...) tem o sentido da continuidade do ser (...). Ela entra na profundidade do ser do animal; é (...) a revelação dessa profundidade (...). Esse elemento é o que é possível nomear (...) de sagrado. O sagrado é justamente a continuidade do ser revelado (...) sobre a morte de um ser descontínuo. Existe (...) ruptura da descontinuidade de um ser: o que subsiste (...) é a continuidade do ser à qual a vítima é devolvida. Somente uma condição de morte (...) é suscetível de revelar o que habitualmente escapa à atenção. (BATAILLE, 2004,128).
\end{abstract}

Ao capturar a borboleta, o estado de torpor em que Benjamin se encontrava cessou. Mas, no retorno a si, passou a enxergar a morte sob outra perspectiva até então nova. "E apesar de tanto estrago (...) e violência, a borboleta assustada permanecia trêmula e, contudo, cheia de graciosidade (...). Era desse modo que penetrava no caçador o espírito daquele ser condenado à morte." (BENJAMIN, 1995, 81). Restituição da condição humana anterior acrescida de um aumento do conhecimento pessoal sobre a beleza: eis o saldo do óbito do animal. A propósito, Bataille $(2004,128)$ acrescenta que a infância constitui etapa privilegiada da vida para experiências desse escol. "Aliás, não poderíamos imaginar o que surge no mais recôndito do ser (...) se não pudéssemos nos referir às experiências (...) que tivemos pessoalmente (...) em nossa infância." Parafraseando Paul Klee (apud Klee, 1962), pode-se afirmar que esse ganho de sapiência derivou da entrada e a saída de um mundo intermediário onde o orgânico, o belo e a finitude da vida interagem livres de cerceamentos.

O trânsito nesta esfera fez com que Benjamin igualmente viesse a identificar aspectos até então velados do comportamento das borboletas em relação às flores.

Ao que the parecia, os dois compartilhavam uma língua oculta, alheia às faladas no

Doutor em Filosofia pela Universidade Gama Filho; e-mail: dirceurng@gmail.com. Brasileiro, residente no Rio de Janeiro - RJ. 
mundo fenomênico. "O idioma no qual presenciara a comunicação entre a borboleta e as flores - só agora entendia algumas de suas leis." (BENJAMIN, 1995, 81). Depois desse, três outros vínculos linguísticos secretos entre palavras e coisas também ficaram evidentes.

O primeiro concerne ao sentido da palavra Brauhausberg. Ela deixou de ser o nome da antiga região das férias de veraneio para se tornar a designação poética do ar onde as borboletas voavam em fuga. "[O] ar no qual se movimentava então aquela borboleta está hoje impregnado por uma palavra que (...) nunca mais ouvi nem pronunciei. (...) O longo estado de silêncio a transfigurou. Assim, naquele ar preenchido pelas borboletas, vibra a palavra Brauhausberg." (BENJAMIN, 1995, 82). O segundo reflete a não menos poética associação do ar intitulado Brauhausberg com a cor azul. "E por isso a Potsdam da minha infância jaz num ar tão azul, como se as [borboletas] estivessem espalhadas na superfície esmaltada de uma porcelana de Limoges, na qual sobressaem no fundo azul as ameias e as muralhas de Jerusalém." (BENJAMIN, 1995, 82). O terceiro e último vínculo consiste justamente nesta imagem emergente da Jerusalém com a mesma tonalidade de Potsdam.

Originais de per si, essas renomeações ratificam que Benjamin testemunhou imagens singulares, inexprimíveis pelas vias da descrição positiva. Daí, a opção por descrevê-las de modo figurado. O recurso à faculdade de imaginar foi determinante para isso. "A imaginação é uma faculdade quase divina que percebe... as relações íntimas e secretas das coisas (...)." (BENJAMIN, 2006, 330).

Comentários esclarecedores sobre o papel da imaginação na capacidade humana de nominar com criatividade são feitos pelo filósofo em diversos momentos do livro das Passagens. Num deles, deixa a entender que o poeta Charles Baudelaire foi alguém que escrevia com rara sensibilidade imaginativa. Para tal, reporta-se ao prefácio que o seu amigo e crítico literário Théophile Gautier escreveu sobre ele na edição de 1863 de "Flores do Mal":

\footnotetext{
Sua maior glória, escreveu Théophile Gautier (prefácio à edição <das Fleurs du Mal> de 1863), "será ter feito entrar nas possibilidades do estilo séries de coisas, de sensações e de efeitos inominados por Adão, o grande nomeador." Ele nomeia... as esperanças e os pesares, as curiosidades e temores que se agitam nas trevas do mundo interior. (BENJAMIN, 2006, 352).
} 
Imaginando, Baudelaire reinventou palavras, sentimentos e significados. Com isso, dilatou assim os horizontes do que podia ser dito e escrito. Segundo o excerto anterior, seu fazer poético redundou em versos tão desconcertantes que Théophile Gautier comparou-o à Adão, o formulador dos nomes primordiais das coisas. "A imaginação... decompõe toda a criação e, com os materiais recolhidos, e dispostos segundo regras cuja origem não podemos encontrar senão no mais profundo, ela cria um mundo novo, produz a sensação do novo." (BENJAMIN, 2006, 335).

Diante do exposto, pode-se sublinhar que a participação no jogo da caça endereçou Benjamin à visitou mundos intermediários, em cujo seio aprendeu a perceber elos idiomáticos até então indiscerníveis entre as borboletas e as flores. Depois desse aprendizado, observou correspondências não menos originais do ar com a cor azul, a sua infância e a sagrada Jerusalém. A imaginação fertilizou o aparecimento dessa cadeia de significações. Por outro lado, ao assim agir, reiterou o modo de poetar de Charles Baudelaire e o ato nominativo originário de Adão.

\section{0 esconde-esconde}

No aforisma "Esconderijos", Benjamin (1995, 91) descreve a brincadeira de esconder-se entre os móveis de casa. Acerca do chão, afirmava: "Conhecia todos os esconderijos do piso e voltava a eles como a uma casa na qual se tem a certeza de encontrar tudo do mesmo jeito. Meu coração disparava, eu retinha a respiração." (BENJAMIN, 1995, 91). Conquanto chegava mais perto do piso, melhor enxergava os mínimos detalhes. "Aqui, ficava encerrado num mundo material que ia se tornando fantasticamente nítido, que se aproximava calado. Só assim é que deve perceber o que é corda e madeira aquele que vai ser enforcado" (BENJAMIN, 1995, 91). Cortina e mesa são igualmente citados: "A criança que se posta atrás do reposteiro se transforma em algo flutuante e branco, num espectro. A mesa sob a qual se acocora é transformada no ídolo de madeira do templo, cujas colunas são as quatro pernas talhadas." (BENJAMIN, 1995, 91). Idem para as portas. "E atrás de uma porta, a criança é a própria porta; é como se a tivesse vestido com um disfarce pesado e, como bruxo, vai enfeitiçar a todos que entrarem desavisadamente." (BENJAMIN, 1995, 91).

Dois aspectos sobressaem-se nestas recordações. O primeiro alude ao fato de que os objetos residenciais possuem singelas minúcias, perceptíveis apenas ao olhar 
que se aproxima delas sem pressa ou pressões de quaisquer ordens. Quando isso acontece, é como se novas descobertas estivessem sendo feitas. Benjamin admite que emoções the afloravam neste estado, chegando mesmo a alterarem os ritmos fisiológicos do corpo. Tal visão reitera o ponto de vista de Bachelard (1988, 93), para quem a casa suscita imagens de intimidade e profundidade, cujo efeito maior consiste em um acréscimo de afetos aos que se deixam vivenciá-las. "[Um] excesso está sempre no ápice de uma imagem viva." Complementa ainda Bachelard $(1988,100)$ que as imagens da casa invocam uma dialética entre o oculto e o visível que transborda a existência pessoal dos indivíduos. "Imaginar será sempre maior que viver."

Transitar pelos corredores, antessalas, quartos e demais cômodos, assim como tocar os objetos em seus interiores, estimula a imaginação a incursionar no que Bachelard $(1988,80)$ chama de circunstância poética da alma. Taxativo, diz o seguinte sobre essa interatividade corporal: "No momento em que (...) um poeta esfrega um móvel - mesmo que por intermédio de outrem -, quando, com um paninho de lã (...) passa um pouco de cera (...) em sua mesa, ele cria um novo objeto, aumenta a dignidade (...) da casa humana." Logo, poetizar a casa representa uma forma de indexá-la a um novo e mais elevado patamar axiológico.

Os objetos (...) acariciados (...) chegam a um nível de realidade mais elevado (...). Propagam uma nova realidade de ser. Assumem não somente o seu lugar numa ordem, mas uma comunhão de ordem. Entre um objeto e outro, os cuidados domésticos tecem vínculos que unem um passado muito antigo ao dia novo (...) até o limite em que o sonho se exacerba. (BACHELARD, 1988, 80).

Na medida em que proporciona ao indivíduo ocultar o seu corpo por entre os objetos domiciliares, o jogo de esconde-esconde do qual Benjamin era adepto remete, de acordo com a perspectiva de Bachelard (1988), a uma atividade cuja execução faz a casa ressurgir com feições novas. Reside justamente aí o segundo aspecto das recordações de Benjamin que cumpre destacar.

De acordo com Caillois $(1990,41)$, as brincadeiras de esconder são casos típicos de mimicry, porque o propósito delas consiste em procurar tornar-se outro enquanto estratégia dissimuladora de si. "O prazer é o de ser um outro ou de se fazer passar por outro." Se o disfarce é bem sucedido, a alegria emerge, e a pessoa chega 
mesmo a ousar reestruturar o ambiente a lhe circunscrever. Com isso, as decisões do brincante na mimicry podem se desdobrar até mesmo em inciativas de alteração das regras do jogo enquanto ele ainda ocorre. A razão é simples: não há como o sujeito imputar diferenciações ao seu corpo e deixar de extrapolá-las aos parâmetros ordenadores do espaço que o cerca.

\footnotetext{
Nestas condições, a mimicry apresenta todas as características do jogo, a saber, liberdade, convenção, suspensão do real e espaço e tempo delimitados. Contudo, a continuada submissão a regras imperativas e precisas é algo que não se verifica (...) já que a dissimulação da realidade e a simulação de uma realidade outra têm nela um lugar. A mimicry é invenção incessante. (CAILLOIS, 1990, 43).
}

Como exemplo dessa propriedade intrínseca da mimicry, o sociólogo cita o caso do ator e da plateia. Entre ambos vige uma sinergia pautada num duplo compromisso estético. "A regra do jogo é uma só: para o ator, consiste em fascinar o espectador, evitando que um erro o conduza à recusa da ilusão; para o espectador, consiste em prestar-se à ilusão sem recusar (...) o artifício em que o convidam a acreditar (...) como um real mais real que o real." (CAILLOIS, 1990, 43). Depreendese do exposto que a mimicry institui uma dinâmica relacional onde ilusão e liberdade interpenetram-se.

Benjamin dá indícios de ter passado por experiências desse naipe enquanto esmerava-se em não ser achado pelos companheiros a rastreá-lo por entre os objetos e cômodos residenciais. "Por nada nesse mundo podia ser descoberta. (...) O que havia de verdadeiro nisso pude vivenciar em meus esconderijos." (BENJAMIN, 1995, 91). O fim da fantasia vinha quando sua posição finalmente acabava visualizada. "Quem me encontrasse era capaz de me petrificar como um ídolo debaixo da mesa (...). Por isso expulsava com um grito forte o demônio que assim me transformava, (...) com um grito de autolibertação. Era assim que não me cansava da luta contra o demônio." (BENJAMIN, 1995, 91). Vê-se que a iminente presença do perseguidor motivava devaneios, que cessavam quando finalmente o esconderijo era encontrado. Tão logo isso ocorria, Benjamin gritava. Essa atitude chancelava o fim da partida e o possível recomeço de outra, rumo novamente ao contexto de livre ficção interrompido.

A opção pelo grito, enquanto medida de afastamento do colega "demônio", encontra justificativa nos estudos de Chevalier \& Gheerbrant (2002) sobre o

Doutor em Filosofia pela Universidade Gama Filho; e-mail: dirceurng@gmail.com. Brasileiro, residente no Rio de Janeiro - RJ. 
simbolismo da voz. Segundo os autores, gritar presume mobilizar a potência do trovão para intimidar adversários. Nesse sentido, o grito traduz uma forma de captação das energias do estrondo do céu para finalidades humanas. Concordando com Chevalier \& Gheerbrant (2002), Buendía (2018) ajuíza que gritar é uma das formas de rechaçar quem tem a intenção de impingir danos à vida. Efetivamente, Benjamin gritou devido ao descontentamento advindo da interrupção do estado lúdico, em que sentia-se fruindo de uma existência plena.

Supõe-se que ao brincar de esconde-esconde, Benjamin ficava mais íntimo de sua casa, porquanto tinha que vasculhar os recônditos mais secretos para ocultar-se. Ao fazê-lo, fantasiava os móveis, cômodos e objetos, atribuindo características oníricas a eles. O seu corpo também era incluído nesse processo. Esse ímpeto criativo é comparável ao fazer poético que agrega novos valores ao mundo, dilatando o seu escopo axiológico, ou então às interpretações dos grandes atores que induzem o público não mais diferenciarem realidade e ficção. Portanto, o brincar de escondeesconde alia ilusão e liberdade.

\section{Faculdade mimética, transformação e ludicidade}

Ao se atentar para as lembranças infantis de Benjamin sobre brincar no carrossel, caçar borboletas e esconder-se por entre os objetos de casa, nota-se que todas são perpassadas por um elemento em comum: a mimetização. Essa condição remonta a uma das teses seminais defendidas por Benjamin, a de que os seres humanos tendem a estabelecer associações de correspondência entre os mais variados entes físicos e não físicos da cultura humana. Tal faculdade humana de buscar semelhanças entre coisas, não obstante a época e o local, recebeu do filósofo o nome de faculdade mimética no ensaio "Teoria das Semelhanças", de 1933. Benjamin $(1992,59)$ insiste que ela perpassa todas as funções humanas consideradas superiores, e tem no jogo infantil a sua raiz primeva.

\footnotetext{
Esta faculdade tem (...) uma história (...). [O] jogo é, em muitos aspectos, a sua escola. Em primeiro lugar, os jogos infantis estão, por toda a parte, impregnados de formas de comportamento miméticas e o seu âmbito não se limita, de modo algum, à imitação dos adultos. A criança brinca não só a fazer de comerciante ou professor, mas também de moinho de vento ou comboio.
}

Doutor em Filosofia pela Universidade Gama Filho; e-mail: dirceurng@gmail.com. Brasileiro, residente no Rio de Janeiro - RJ. 
Considerando que os velozes ciclos do carrossel, a caça das borboletas e o esconde-esconde são meios de estímulo à faculdade mimética, também é nítido que os usos dela nessas atividades endereçaram Benjamin a contextos epistêmicos e axiológicos não menos ímpares. Dito de outro modo, mimetizar permitiu-lhe interagir com universos alternativos (mundos intermediários, na acepção de Paul Klee). À guisa de recapitulação, enquanto era levado pelos volteios giratórios, foi invadido pela sensação de estar protagonizando aventuras mitológicas. Essa experiência o fez reviver a fé perene na salvação e esperança, que são os pilares fulcrais do Jetztzeit judaico. Por outro lado, ao imaginar-se como um astuto caçador, teve a impressão de projetar-se para mundos supra fenomênicos onde as coerções materiais haviam desaparecido. Deles, foi remetido ao terreno das linguagens adâmicas, onde o ente é unido ao seu nome de maneira absoluta. Por fim, enquanto escondia-se, atribuiu conotações oníricas atribuídas à objetos residenciais que dialeticamente redundaram no despertar de um intenso sentimento de libertação, encontrável apenas no fazer teatral ou no poetar.

Ora, cada qual em sua singela condição estrutural, os jogos/brincadeiras em questão redundaram na produção de cadeias diversificadas de sentidos nem um pouco unívocos ou determinísticos. Mesmo passados muitos anos, a memória de Benjamin preservou essa polissemia, que é típica das figurações alegóricas.

A alegorização, diz Brandão (1997), equivale a um processo ficcional de modelação dos sentimentos e da cognoscibilidade em relação a conteúdos materiais e imateriais, onde um objeto é mencionado para dar ideia de algum outro, e assim sucessivamente. Trata-se de uma criação mental que consiste em mobilizar valores atrelando-os a divindades, personagens literários, animais e pessoas. ${ }^{2}$ Segundo Merquior (1969, 104-105) as alegorias pressupõem a fungibilidade do particular. "[No] mundo alegórico, cada objeto pode representar um outro. (...) Mas essa mesma alusividade dos objetos os torna mágicos e atraentes; o mundo indiferenciado se converte num tesouro de sentido." Concordando com Merquior (1969) e Brandão (1997), Duvignaud (1997, 99-100) pontua que alegorizar subentende o desejo de metamorfosear.

\footnotetext{
${ }^{2}$ Daí, a etimologia do termo alegoria significar dizer outra coisa.

Doutor em Filosofia pela Universidade Gama Filho; e-mail: dirceurng@gmail.com. Brasileiro, residente no Rio de Janeiro - RJ.
} 
He allí, el motor de uma fascinación: la metamorfoses implica (...) el cambio de forma mas allá de todo determinismo y toda racionalidade (...). Que una doncella, perseguida por um dios, se convierta em árbol, que um dios se transforme en animal para llegar a aquella que desea es algo que recurre a (...) una visión mágica del cosmos (..... ${ }^{3}$

Na obra "Oasis de la felicidad. Pensamientos para una ontología del juego", Fink (1966) refere-se a essa relação criativa como sendo a mais frequente de existir no jogo. Chamando-a de abertura lúdica, afirma tratar-se de uma situação ímpar da experiência humana, porque exige o diálogo do ser do sujeito com alteridades, assim como a admissão das propriedades ônticas que ratificam a sua finitude. "El verdadeiro ser del juego es la transformación em el sentido de que la identidad del que juega no se mantiene para nadie, juego es entonces una construcción que se presenta o construye a sí mesma como una totalidade de sentido." (FINK, 1966, 23).

Se a dinâmica do jogo permite modificações nas identidades, então as fronteiras conceituais entre ser e não ser diluem-se nas ocasiões lúdicas. "The world of play does not interpose a wall between us and being that surrounds us (...). It is a product of the imagination and does not relate to the categories of truth and error as does the representation and objects represented." (FINK, 1988, 155). Como corolário, pode-se dizer que a imaginação lúdica consiste em potência do espírito humano produtora de novos mundos. "The world of play is an imaginary sphere. (...) We play in the world we call real, but in so doing, we create for ourselves another world, a mysterious one." (FINK, 1988, 152).

Adicionalmente, Fink (1988) compara a situação do jogador a de um indivíduo portador de uma "esquizofrenia" não patológica. De um lado, quando ele opta por jogar, sabe que deverá exercer funções conscientes. Todavia, se escolheu jogar, igualmente tem ciência de que precisará performatizar papéis. Este panorama mostra que a imersão no jogo aglutina fantasia e racionalidade de modo não alucinatório ou patológico. O jogar desloca o sujeito do contexto real-concreto para territórios fictícios, e vice-versa. "There is a real basis for saying that the player loses himself $(\ldots)$ with a very particular intensity and, for that reason, not in the manner $(. .$.$) where we cannot$

\footnotetext{
${ }^{3}$ Possivelmente, a transformação de um Deus em animal para se achegar à mulher que deseja citada por Duvignaud (1997) é a de Zeus em touro, cujo propósito foi conquistar a confiança de Europa. No presente estudo, Benjamin reviveu esse episódio durante o carrossel.
}

Doutor em Filosofia pela Universidade Gama Filho; e-mail: dirceurng@gmail.com. Brasileiro, residente no Rio de Janeiro - RJ. 
distinguish "reality" from "illusion." (FINK, 1988, 152). Mesmo admitindo que se trata de situação envolta em ambiguidades, o jogador crê que pode controlá-lo. "Even engrossed, the consciousness of his double existence does not abandon him. He lives in two worlds (...). The duality belongs to the very nature of play." (IBID).

Em suma, a abertura lúdica estimula alegorizações, polissemias e metamorfoses nas representações correntes sobre o ordenamento dos valores, signos e entes. Outrossim deve-se salientar que Heráclito de Éfeso e Nietzsche investigaram o mesmo problema.

Para o pensador pré-socrático, o cosmos correspondia a uma totalidade marcada pela falta de permanências e pelo primado da destrutibilidade. Tudo se encontra nele em pleno estado de contrariedades. "Para os ventos, morte vem a ser água, para a água, morte vem a ser terra; mas da terra nasce água, da água, vento." (HERÁCLITO APUD CARNEIRO LEÃO, 2005, 67). Por mais que as intervenções humanas visem imputar estabilidade ao mundo, elas ampliam a sua entropia e imprevisibilidade. "O mistério: dia-noite, inverno-verão, guerra-paz, saciedade-fome, cada vez que entre fumaça recebe um nome segundo o gosto de cada um, se apresenta diferente." (HERÁCLITO APUD CARNEIRO LEÃO, 2005, 77). Não há como subjugar o existir, pois ele é intempestivo e alheio a controles, aduz Heráclito. "O mundo, o mesmo em todos, nenhum dos deuses e nenhum dos homens o fez mas sempre foi, é e será, fogo sempre vivo, ascendendo segundo a medida e segundo a medida apagando." (HERÁCLITO APUD CARNEIRO LEÃO, 2005, 67). Consequentemente, o mundo impõe-se como negação de consistências e perpétuo vir-a-ser. A transformação conflituosa de formas e conteúdos é a lei suprema do Cosmos. "O contrário em tensão é convergente; da divergência dos contrários, a mais bela harmonia." (HERÁCLITO APUD CARNEIRO LEÃO, 2005, 61). Afirma Heráclito que a imagem a melhor sintetizar a perenidade do vir-a-ser cósmico é a do brincar/jogar desimpedido do infante. "O tempo é uma criança criando, jogando o jogo de pedras; vigência da criança." (HERÁCLITO APUD CARNEIRO LEÃO, 2005, 73).

Nietzsche $(1978,36)$ retoma o argumento de Heráclito, acrescentando que a instabilidade do vir-a-ser constitui a norma suprema de justiça no Cosmos. Apenas os ressentidos consideram-na uma aberração. "Há (...) contradição, sofrimento, neste mundo? Sim, (...) para o homem limitado (...), não, para àquele que, como Heráclito, 
é (...) contemplativo." Nietzsche insiste que a criança que brinca/joga e o fazer desimpedido do artista retratam com fidedignidade esse que é o fundamento estrutural da realidade.

\begin{abstract}
Um vir-a-ser e parecer, um construir e destruir, sem nenhuma prestação de contas de ordem moral, só tem neste mundo o jogo do artista e da criança. E assim como joga a criança e o artista, joga o fogo eternamente vivo (...) o Aion consigo mesmo. ${ }^{4}$ Transformando-se em água e terra, faz, como uma criança, montes de areia à borda do mar, faz e desmantela; de tempo em tempo começa o jogo de novo. Um instante de saciedade: depois a necessidade o assalta de novo (...). Não é o ânimo criminoso, mas o impulso lúdico, que, sempre despertando de novo, chama à vida outros mundos. Às vezes a criança atira fora o seu brinquedo: mas logo recomeça, em humor inocente. Mas, tão logo constrói, ela o liga, ajusta e modela, regularmente, e segundo ordenações internas. (IBID).
\end{abstract}

$\mathrm{Na}$ interpretação de Machado (2005), o diagnóstico anterior de Nietzsche sugere que o jogo e a brincadeira são investidos de uma hybris que rompe com as medidas delimitadoras. Ambos engendram a desmesura e o excesso imprescindíveis ao livre criar.

Tal qual Nietzsche, Benjamin $(2002,92)$ registrou, com a seguinte observação, esta disposição no artigo "História cultural do brinquedo". Nas suas palavras: "De um lado, (...) nada é mais adequado à criança do que irmanar em suas construções os materiais mais heterogêneos - pedras, papel (...). Por outro, (...) uma pinha ou pedrinha reúnem, (...) na solidez (...) de sua matéria, uma exuberância [de] figuras." Já no ensaio "Visão do livro infantil", o filósofo extrapola essas colocações à corporeidade. "É que o próprio ser humano corresponde a toda forma, a todo traço que ele percebe, na sua capacidade de produzi-los. O próprio corpo (...) reproduz os elementos de sua percepção e os incorpora a si." (BENJAMIN, 2002, 78). Ou seja, inovações lúdicas absorvem igualmente os segmentos do corpo.

Em síntese, o jogar e o brincar envolvem o acionamento da faculdade mimética. Os dizeres de Benjamin em "Rua de Mão Única" sobre quando girava no carrossel, caçava borboletas e escondia-se dentro de casa corroboram este comportamento. Por seu turno, mimetizar permite produzir polissemias de sentidos. Essa ação é

\footnotetext{
4 Zourabichvili (2004) compreende a ideia de "jogar o Aion" como o conjunto de interações ocorridas em um "entre-tempo", que também seria um "tempo flutuante". Ele destoa do tempo homogêneo cronológico porque marca a irrupção de uma cesura, ou corte, na brevidade do instante. Neste nível, os eventos sucedem-se por diferenciações imanentes que repercutem sobre a estrutura do sujeito pelo fato de inserirem-se na sua constituição existencial. $O$ jogo e a brincadeira providenciariam a virtual penetração da pessoa nesse tempo flutuante.
}

Doutor em Filosofia pela Universidade Gama Filho; e-mail: dirceurng@gmail.com. Brasileiro, residente no Rio de Janeiro - RJ. 
reconhecida por diferentes designações conceituais, a depender de como é abordada: alegorização, abertura lúdica, metamorfose etc. são alguns dos termos empregados. O encaminhamento dessa ordem de transformações indexa o brincar e o jogar à condição de territórios do vir-a-ser, em cujas tessituras vige uma hybris rompedora das estabilidades ônticas. Epistemologicamente, as colocações de Heráclito de Éfeso e Nietzsche reforçam essa tese.

\section{CONCLUSÃO}

O objetivo do presente estudo foi investigar a hipótese de que jogos e brincadeiras constituem veios de acesso metafísico a mundos intermediários, tal qual a definição encaminhada por Paul Klee. Para isto, partiu do pressuposto que os aforismas "O carrossel", "Caçando borboletas" e "Esconderijos", contidos no texto "Infância em Berlim por volta de 1900", poderiam ser vistos como documentos de memória onde estão localizados rastros dessa experiência.

A análise e interpretação comentadas dos aforismas listados mostrou que os jogos e brincadeiras neles descritos conseguiam endereçar Benjamin a universos oníricos que se encadeavam de maneira não linear e polissêmica, onde outros matizes da realidade puderam ser vivenciados. $O$ uso da faculdade mimética insurgiu como o gatilho deflagrador desses processos. A imersão em tais cenários fez com Benjamin ampliasse compreensões nos campos da axiologia, estética e epistemologia. Conclui-se daí que os mesmos viabilizaram situações de aprendizado que, possivelmente, não lhe aconteceriam em outros cenários.

Recomenda-se que futuras investigações levantem se outros aforismas escritos por Benjamin em "Rua de Mão Única" ou "Infância em Berlim por volta de 1900" discorrem sobre a mesma temática. Também compete levantar se há remissões à ela nos ensaios não aforísticos escritos pelo autor. No mais, o presente estudo fornece argumentos que endossam a relevância educacional de uma pedagogia lúdica e centrada no estímulo à mimetização.

\section{REFERÊNCIAS}


ADORNO, Theodor. Caracterização de Walter Benjamin. In : BENJAMIN, Walter. Sobre arte, técnica, linguagem e política. Trad. Maria Luiz Moita. Lisboa: Relógio D’Água, 1992, p. 9-26.

BACHELARD, Gaston. A poética do espaço. Trad. Antonio de Padua Danesi. São Paulo: Martins Fontes, 1988.

BATAILLE, G. O erotismo. Trad. Claudia Fares. São Paulo: Arx, 2004.

BENJAMIN, Walter. Passagens. Trad. Cleonice Paes Barreto Mourão e Irene Aron. Belo Horizonte: Editora UFMG; São Paulo: Imprensa Oficial do Estado de São Paulo, 2006.

. História cultural do brinquedo. In:__ Reflexões sobre a criança, o brinquedo e a educação. Trad. Marcus Vinicius Mazzari. São Paulo: Duas Cidades; Ed. 34, 2002, p. 89-94.

Visão do livro infantil. In: Reflexões sobre a criança, o brinquedo e a educação. Trad. Marcus Vinicius Mazzari. São Paulo: Duas Cidades, 2002, p. 69-80.

. Caçando borboletas. In : Rua de Mão Única. Trad. Rubens Rodrigues Torres Filho e José Carlos Martins Barbosa. São Paulo: Brasiliense, 1995, p. 80-82.

. Canteiro de Obras. In : Rua de Mão Única. Trad. Rubens Rodrigues Torres Filho e José Carlos Martins Barbosa. São Paulo: Brasiliense, 1995, p. 18-19.

. Esconderijos. In : Rua de Mão Única. Trad. Rubens Rodrigues Torres Filho e José Carlos Martins Barbosa. São Paulo: Brasiliense, 1995, p. 91.

O Carrossel. In : Rua de Mão Única. Trad. Rubens Rodrigues Torres Filho e José Carlos Martins Barbosa. São Paulo: Brasiliense, 1995, p.106.

- Teoria das Semelhanças. In : Sobre arte, técnica, linguagem e política. Trad. Maria Amélia Cruz. Lisboa: Relógio D’Água, 1992, p. 59-65.

. Teses sobre a filosofia da história. In : Sobre arte, técnica, linguagem e política. Trad. Manuel Alberto. Lisboa: Relógio D’Água, 1992, p. 157170.

BRANDÃO, Junito. Mitologia Grega. Petrópolis: Vozes, 1997 (vol. I).

BUENDÍA, Maritza Manríquez. El simbolismo del grito em Jamás, nadie, de Beatriz Rivas. Impossibilia. Revista Internacional de Estudios Literarios. No. 16 (Noviembre 2018). Páginas 28-51. 
CAILLOIS, Roger. Os Jogos e os Homens. A máscara e a vertigem. Trad. José Garcez Palha. Lisboa: Cotovia, 1990.

CARNEIRO LEÃO, Emmanuel. Os pensadores originários: Anaximandro, Parmênides, Heráclito. Trad. Emmanuel Carneiro Leão e Sérgio Wrublewski. Petrópolis: Vozes, 2005.

CHEVALIER, Jean; GHEERBRANT, A. Trad. Vera da Costa e Silva, Raul de Sá Barbosa, Angela Melim e Lúcia Melim. Dicionário de Símbolos. Rio de Janeiro: José Olympio, 2002.

CROMBERG, Monica Udler. Tempo e história: algumas aproximações acerca do presente em Walter Benjamin e em Martin Buber. Cadernos de Filosofia Alemã, v. 8, p. 41-59, 2002.

DUVIGNAUD, Jean. El juego del juego. Trad. Jorge Ferreiro Santana. Bogotá: Fondo de Cultura Económica, 1997.

FINK, Eugen. Oasis de la felicidad. Pensamientos para una ontología del juego. Trad. Elsa Cecilia Frost. México, DF: Universidad Autónoma de México, 1966. . The Ontology of Play. In: MORGAN, William J./ MEIER, Klaus V. (Ed.). Philosophic Inquiry in Sport. Champaign, IL: Human Kinetics Publishers, 1988, p.145-157.

GAGNEBIN, Jeanne Marie. Lembrar, escrever, esquecer. São Paulo: Ed. 34, 2006. Imago, 2005. Sete aulas sobre linguagem, memória e história. Rio de Janeiro:

GRIMAL, Pierre. Dicionário da Mitologia Grega e Romana. Trad. Victor Jabouille. Rio de Janeiro: Bertrand Brasil, 2000.

KLEE, Felix. Paul Klee: His Life and Works in Documents. New York: George Braziller, 1962.

MACHADO, Roberto. Nietzsche e a polêmica sobre $\boldsymbol{O}$ Nascimento da Tragédia. Rio de Janeiro: Jorge Zahar, 2005.

MATOS, Olgária. Desejo de evidência, desejo de vidência: Walter Benjamin. In: NOVAES, Adauto (Org.). O desejo. São Paulo: Companhia das Letras, 1990, p. 283-305.

MERQUIOR, José Guilherme. Arte e Sociedade em Marcuse, Adorno e Benjamin. Rio de Janeiro: Tempo Brasileiro, 1969. 
NIETZSCHE, Friedrich. A Filosofia na Época Trágica dos Gregos. In: Obras incompletas. Trad. Rubens Rodrigues Torres Filho. São Paulo: Abril Cultural, 1978, p. 30-42. [Coleção Os Pensadores].

SCHOLEM, Gershom. O Golem, Benjamin, Buber e outros Justos: Judaica I. São Paulo: Perspectiva, 1994.

Walter Benjamin: a história de uma amizade. São Paulo: Perspectiva, 1994.

ZOURABICHVILI, François. O vocabulário de Deleuze. Rio de Janeiro: RelumeDumará, 2004. 